\title{
Protein expression of the chemokine, CCL28, in human colorectal cancer
}

\author{
JAN DIMBERG $^{1}$, ANDERS HUGANDER $^{2}$ and DICK WÅGSÄTER ${ }^{3,4}$ \\ ${ }^{1}$ Department of Natural Science and Biomedicine, University College of Health Sciences, Box 1026; \\ ${ }^{2}$ Department of Surgery, Ryhov County Hospital, SE-551 11 Jönköping; ${ }^{3}$ Division of Biomedicine, Department of \\ Caring Sciences, University of Örebro, SE-701 82 Örebro; ${ }^{4}$ Atherosclerosis Research Unit, King Gustav V \\ Research Institute, Department of Medicine, Karolinska Institute, SE-171 76 Stockholm, Sweden
}

Received September 5, 2005; Accepted October 28, 2005

\begin{abstract}
Accumulating evidence points out that chemokines play important roles in colorectal mucosal immunity by recruiting leukocytes into and out of the lamina propria adjacent to the epithelium. The chemokine, CCL28, which is expressed by epithelial cells within colorectal mucosa is thought to have dual roles as a chemoattractant for leukocytes expressing CCR10 and/or CCR3 and a mediator of antimicrobial activity. To date, there is little known about the presence of CCL28 in colorectal cancer. The objective of this study was to determine whether the CCL28 protein level is altered in colorectal tumours $(n=76)$ compared with paired normal mucosa. Further, the plasma CCL28 levels from patients with colon and rectal cancer were also examined. Immunohistochemistry revealed heterogeneous CCL28 protein expression in tumour and normal epithelial cells. Analyses by ELISA showed that the CCL28 protein level in colon tumours was significantly $(\mathrm{P}<0.001)$ lower than in normal tissue and that the difference in CCL28 protein level between rectal tumour and normal tissue was not significant. Patients with a tumour localized in the colon had significantly $(\mathrm{P}<0.05)$ higher plasma CCL28 protein levels than patients with a tumour localized in the rectum. These discrepancies may suggest that there are different mechanisms and signalling pathways involved in the pathogenesis of cancer in the colon and rectum and thereby differentially promote the expression and secretion of CCL28 protein. Further studies on CCL28 protein in colorectal cancer with an extended number of patients are necessary to conclude whether tissue levels and plasma concentrations carry significant clinical relevance.
\end{abstract}

Correspondence to: Dr Jan Dimberg, Department of Natural Science and Biomedicine, University College of Health Sciences, Box 1026, SE-551 11 Jönköping, Sweden

E-mail: jan.dimberg@hhj.hj.se

Key words: MEC, CCL28, protein expression, colorectal cancer

\section{Introduction}

Colorectal cancer (CRC) is one of the most common cancer diseases in Western countries. A number of genetic alterations within oncogenes and tumour suppressor genes in epithelial cells have been associated with the adenoma-carcinoma sequence in cancer development $(1,2)$.

Local immunoregulation mediated by infiltration of inflammatory cells into colorectal adenocarcinomas is considered of importance for tumour progression (3). Tumour-associated leukocytes play an important antitumourigenic role but have also been shown to contribute to the growth and spread of malignancy (4-6).

Different chemokines (chemotactic cytokines) are variably expressed in a number of cancers and provide directional stimulus for the movement of leukocytes in cancers (7). Chemokines are major determinants of macrophage and lymphocyte infiltration in human carcinomas (7).

In the gastrointestinal tract, intestinal mucosa regulates the trafficking of leukocytes into and out of the lamina propria adjacent to the epithelium. This may reflect the production of chemokines by the intestinal epithelium $(8,9)$.

The chemokine, CCL28, also termed MEC (mucosaeassociated epithelial chemokine), is expressed by epithelial cells within the large intestine and at a lower level in the small intestine $(10,11)$. This chemokine is a ligand for the receptors, CCR10 and CCR3, and chemoattract CD4/CD8 T cells, IgA B cells and eosinophils (10-13). Furthermore, it has been suggested that CCL28 is constitutively secreted by intestinal epithelial cells and functions as a potent antimicrobial factor and protects the mucosa surface against colonizing microbes (13). In addition to the large and small intestine, CCL28 is also constitutively expressed in different mucosal sites, including the bronchial, salivary and mammary glands $(10,11)$. It has been reported that CCL28 is up-regulated in inflamed human colon epithelium (12) and highly reduced or eliminated in human breast tumours compared to normal adjacent tissue (14).

To our knowledge, little is known about the expression of CCL28 in human CRC. Therefore, we find particular reason to study CCL28 expression in the specimens of cancerous and adjacent non-cancerous tissues and levels of CCL28 protein in plasma from CRC patients. 


\section{Patients and methods}

Patients and tissue sampling. This study comprised tissue samples, which were obtained from 76 patients who underwent surgical resections for primary colorectal adenocarcinomas diagnosed at the Department of Surgery, Ryhov County Hospital, Jönköping, Sweden. Sporadic tumours from 40 male and 36 female subjects with a mean age of 70 years (range 36-93) were collected and classified according to Dukes' classification system: stage A $(n=11)$, stage B $(n=31)$, stage $C(n=29)$ and stage $D(n=5)$. The tumours were localized in the colon $(n=35)$ and rectum $(n=41)$. From each patient, tumour tissue and adjacent normal mucosa (about $5 \mathrm{~cm}$ from the tumour) were excised and immediately frozen at $-70^{\circ} \mathrm{C}$ until analysis.

Plasma samples. Forty-four of the patients were available for plasma collection. Venous blood was collected before surgery and separated by centrifugation within $1 \mathrm{~h}$. Plasma was removed and stored at $-70^{\circ} \mathrm{C}$ until assayed.

Protein preparation. Frozen tumour tissue and normal mucosa were thawed, homogenised in ice-cold lysis buffer containing PBS (9.1 mM dibasic sodium phosphate, $1.7 \mathrm{mM}$ monobasic sodium phosphate, $150 \mathrm{mM} \mathrm{NaCl}, \mathrm{pH} 7.4$ ) and $1 \%$ Nonidet $\mathrm{P}-40,0.5 \%$ sodium deoxycholate, $0.1 \%$ sodium dodecyl sulphate (SDS), $100 \mu \mathrm{g} / \mathrm{ml}$ phenylmethylsulphonyl flouride (PMSF), $2 \mu \mathrm{g} / \mathrm{ml}$ aprotinin, $1 \mathrm{mM}$ sodium orthovanadate and $1 \mu \mathrm{g} / \mathrm{ml}$ leupeptin. The lysate was placed on ice for $30 \mathrm{~min}$ and then centrifuged at $13000 \mathrm{x} \mathrm{g}$ for $10 \mathrm{~min}$. The protein content of the supernatant fluid was determined for each sample using the Lowry assay (15).

ELISA. The CCL28 protein levels of cancer and paired normal tissues from 76 patients were measured using an established commercially available enzyme-linked immunosorbent assay (ELISA) kit (R\&D Systems Europe, UK). The level of plasma CCL28 protein was determined using the same kit. The CCL28 protein level was expressed as $\mathrm{pg} / \mathrm{mg}$ of protein and the plasma CCL28 protein concentration was expressed as $\mathrm{pg} / \mathrm{ml}$. All analyses were performed in duplicate and the mean values were used for statistical calculations.

Immunohistochemistry. Ten of the 76 tumour samples were available for immunohistochemical staining to study the cell type origin of the CCL28 expression. Staining was performed, using a standard protocol on sections from formalin-fixed paraffin-embedded tissue blocks. The sections were incubated overnight at $4^{\circ} \mathrm{C}$ with primary mouse anti-human monoclonal CCL28 antibody (R\&D Systems) diluted 1:100. After rinsing in tris-buffered saline, sections were incubated with secondary biotinylated rabbit anti-mouse IgG (Dako Cytomation, Denmark). Avidin-biotin peroxidase complexes (Dako Cytomation) were added followed by visualization with 3.3'diaminobenzidine tetrahydrochloride (Dako Cytomation). All sections were counterstained with Mayer's hematoxylin (Histolab Products AB, Sweden).

Statistical analysis. Data are presented as mean values \pm standard error of the mean (SEM). Differences of CCL28
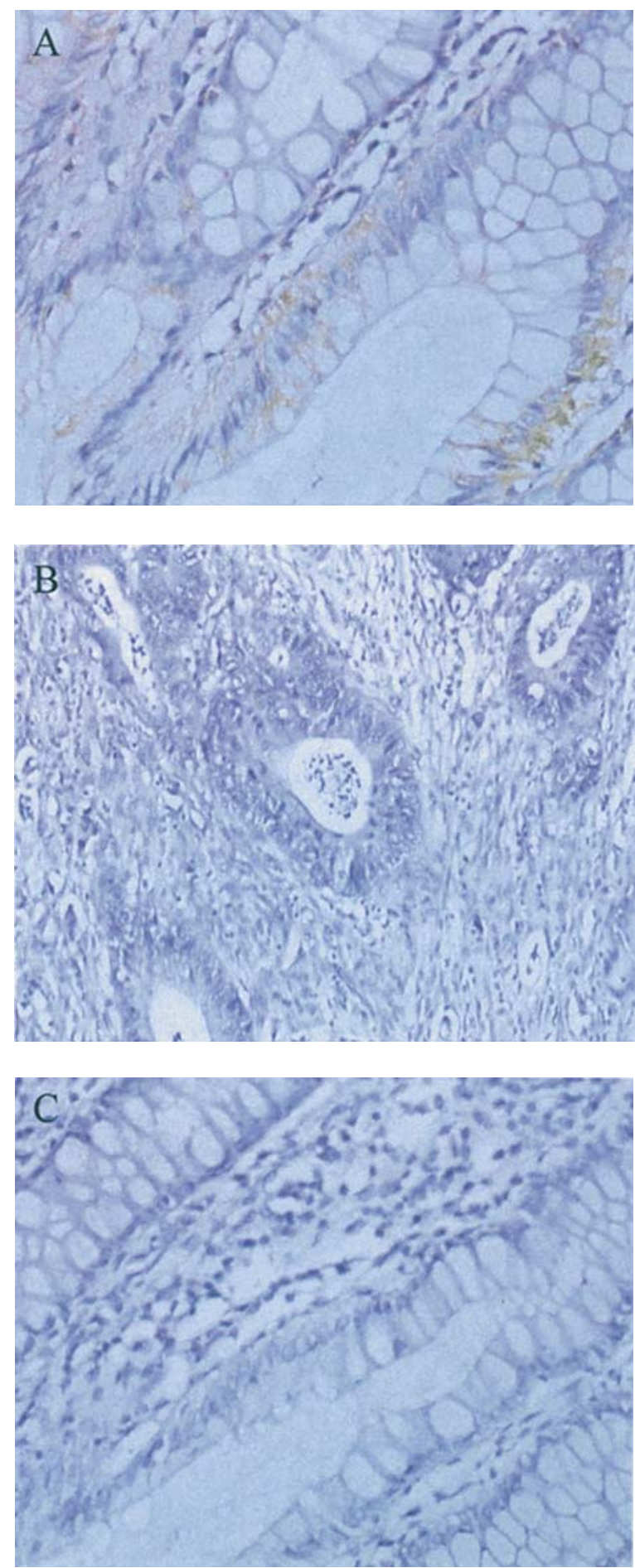

Figure 1. Immunohistochemical detection of CCL28 and localization in human colorectal cancer. CCL28 protein expression is present in normal epithelial cells (A) and to a lower extent in cancerous tissue (B). Control staining of normal tissue $(\mathrm{C})$ with only the secondary antibody, demonstrating the specificity of the primary antibody.

protein expression between tumour and paired normal tissue were examined by the Wilcoxon signed rank test. Differences of CCL28 protein expression between unpaired groups were examined by the Mann-Whitney U test. Statistical analysis was performed using the SPSS for Windows computer package (Rel. 11.5, 2002, Chicago: SPSS Inc.). Results were considered significant at a level of $\mathrm{P}<0.05$. 


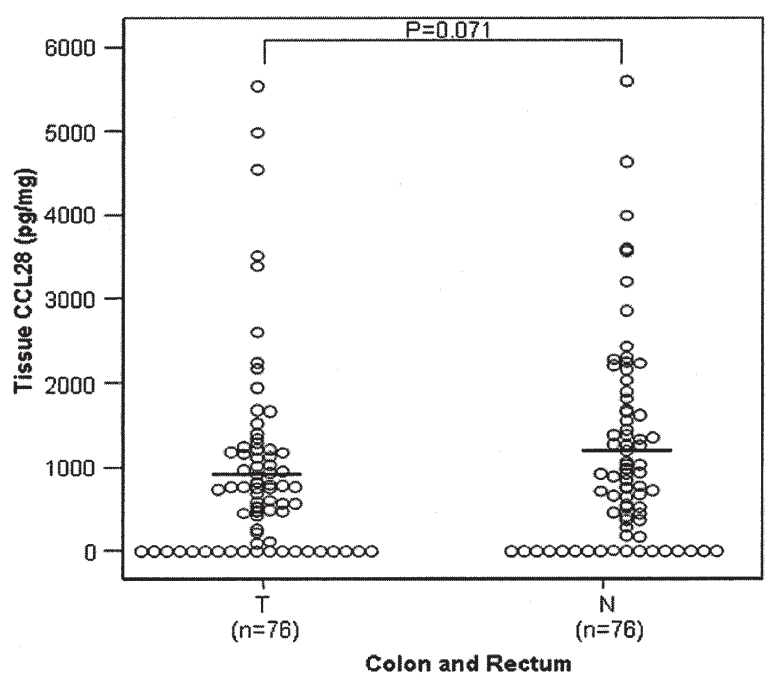

Figure 2. Relationship between CCL28 protein levels in human colorectal cancer $(\mathrm{T})$ and matched normal tissue $(\mathrm{N})$. The CCL28 protein level in cancerous tissue tends to be suppressed in relation to normal tissue. Means are shown by horizontal bars.

\section{Results}

Immunohistochemical findings. Immunohistochemistry was performed in order to detect the site of expression of CCL28 protein. Fig. 1 shows immunohistochemical staining of CCL28 protein. CCL28 immunoreactivity was observed both in colorectal carcinoma cells and in the resection border that reflects normal epithelial cells. The observations showed a heterogeneous staining of CCL28 protein in cancerous as well as non-cancerous tissue. Overall, CCL28 was predominantly localized in normal epithelial cells and showed an intensity of staining varying from none to strong whereas carcinoma cells showed no and occasionally weak to strong immunoreactivity. In the surrounding stroma, no cells were stained and control staining using only the secondary antibody showed no reactivity.

Protein levels of CCL28 in tissue and plasma. CCL28 protein concentration was measured by ELISA in protein-lysates of colorectal cancerous tissue and matched normal tissue from 76 patients. Fig. 2 shows that, in most cases, measurable amounts of CCL28 protein were found. When assessing these levels we found undetectable CCL28 protein expression in 3 colon and 3 rectal tumours as well as corresponding normal tissue. Evaluation of the relative expression (tumour vs normal tissue) showed $31.6 \%$ (24/76) up-regulation and 60.5\% (46/76) suppression. The levels of CCL28 protein in cancerous tissue $(937 \pm 107.5 \mathrm{pg} / \mathrm{mg})$ were found to be lower when compared with normal tissue $(1149 \pm 131.8 \mathrm{pg} / \mathrm{mg})$. However, the difference was not significant $(\mathrm{P}=0.071)$.

When subdividing the patients (Fig. 3) into groups of colon $(n=35)$ and rectum $(n=41)$, we found an up-regulation of $20 \%$ $(7 / 35)$ and suppression of $71.4 \%(25 / 35)$ in the colon cases. The CCL28 protein level in colon cases was $696 \pm 117.6 \mathrm{pg} / \mathrm{mg}$ in cancer tissue, which was significantly lower than the $1182 \pm 199.8 \mathrm{pg} / \mathrm{mg}$ level in normal colon tissue $(\mathrm{P}<0.001)$.

In the rectum cases, $41.5 \%$ (17/41) were up-regulated and $51.2 \%(21 / 41)$ were suppressed when comparing the CCL28

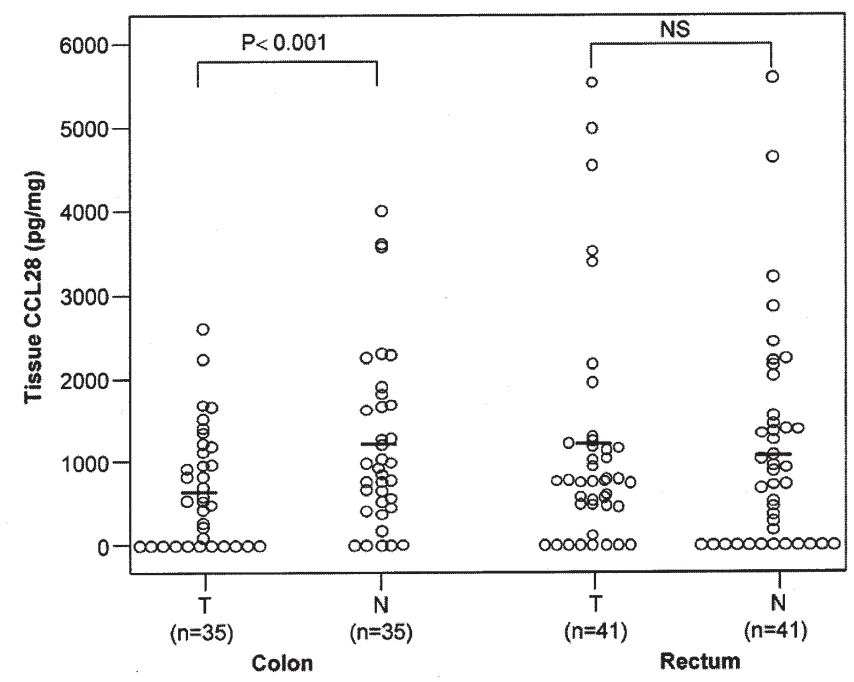

Figure 3. Comparison of CCL28 protein levels in human colon and rectal cancer $(\mathrm{T})$ in relation to matched normal tissue $(\mathrm{N})$. The tissue level of CCL28 protein in colon cancer has a significantly lower value versus paired normal tissue. The difference of CCL28 protein level between rectal tumour and paired normal tissue was not significant (NS). Means are shown by horizontal bars.

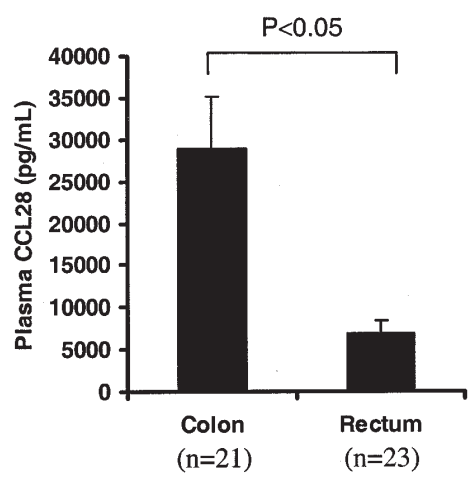

Figure 4. Plasma CCL28 protein concentration in human colorectal cancer. Patients with colon cancer have a significantly higher CCL28 protein concentration compared to patients with rectal cancer.

protein expression in tumours with adjacent normal tissue. The CCL28 protein level in rectal cancerous tissue $(1142 \pm 178.4 \mathrm{pg} /$ $\mathrm{mg}$ ) was not significantly different compared with the level in normal rectal tissue $(1121 \pm 175.1 \mathrm{pg} / \mathrm{mg})$.

Fig. 4 shows that patients with a tumour localized in the colon $(n=21)$ had a significantly $(P=0.033)$ 4-fold higher plasma concentration $(28951 \pm 6317.7 \mathrm{pg} / \mathrm{ml})$ than patients with a tumour localized in the rectum $(\mathrm{n}=23)(7010 \pm 1461.7 \mathrm{pg} / \mathrm{ml})$.

The levels of CCL28 protein, in all analyzed tissues and plasma, did not correlate with clinical characteristics such as age, gender and Dukes' stage.

\section{Discussion}

Chemokines are chemotactic cytokines that regulate the trafficking of leukocytes. Some of the chemokines play an important role in lymphocyte homing and localization to the intestine. For example, the chemokine, TECK/CCL25, is solely expressed to epithelial cells within the small intestine 
and has specificity of CCR9+ lymphocytes which affect the intestinal immunity (16-19). Interestingly, single nucleotide polymorphism in CXCL8 is associated with a reduced risk of colorectal cancer (20) and the expression level of $\mathrm{CX}_{3} \mathrm{C}$ chemokine was found to be an essential biomarker for predicting the prognosis of patients with CRC (21). We have also previously shown that the level of CXCL16 is significantly lower in rectal cancer compared to normal tissue (22).

CCL28 is one of the recently discovered CCL chemokines. Prior studies have shown that the chemokine, CCL28, is constitutively expressed in mucosal cells within the large intestine and has a function in mucosal immunity $(10-13,23)$. This chemokine is suggested to play a role in the homeostatic trafficking of CD4 T, CD8 T, IgA B cells and eosinophils. It also has a broad spectrum of antimicrobial activity (13).

In the current study, we used immunohistochemistry to discriminate the origin of the CCL28 protein expression in $\mathrm{CRC}$ and normal colorectal tissue. The investigation revealed heterogeneous CCL28 protein expression in cancer and normal tissues. In normal colorectal tissue, CCL28 was expressed in epithelial cells with no to strong immunoreactivity. In cancerous tissue, CCL28 was not expressed but occasionally showed a weak to strong immunoreactivity.

Using ELISA, we noted a trend $(\mathrm{P}=0.071)$ regarding a lower mean concentration of CCL28 protein in cancerous tissue than in normal tissue. We also demonstrated that there was a notable suppression of CCL28 protein in $71.4 \%$ of colon tumours compared with adjacent normal mucosa $(\mathrm{P}<0.001)$. This significantly lower value of CCL28 protein expression in colon cancer may reflect one of the immunological disorders in cancer-burden states. It may be assumed that this phenomenon is associated with changes in gene regulation and/or differentiation and immune response in colon tumours. However the biological significance of the observed difference remains open as long as the underlying mechanisms are unclear.

The rectum samples revealed no significant difference between the CCL28 protein levels in tumour tissue and those in adjacent normal tissue. Hypothetically, different mechanisms might be involved in the pathogenesis of cancer in the colon and rectum and, thereby, different signalling pathways can differentially promote the expression of CCL28 by affecting pre-/post-transcriptional regulatory mechanisms. We suggest a significant role of suppressed CCL28 protein expression in CRC since suppressed levels of CCL28 protein may lead to less trafficking of leukocytes to the tumour. The suppression of CCL28 protein could be a strategy by tumours to escape confrontation with tumour infiltrating leukocytes and disorder the intestinal immunity. We also showed that patients with colon cancer had higher plasma CCL28 protein levels compared with patients with rectal cancer. This discrepancy may in part be explained by the biological difference between the two tumour types and different carcinogenesis pathways which influence the secretion of CCL28 protein. Extended research is required to confirm this possibility based on more clinical cases.

In studies of CCL28 regulation using human colon epithelial cells, proinflammatory stimuli, such as IL-1, significantly upregulated CCL28 (12). To our knowledge, no studies have been published about regulation of CCL28 in rectal epithelial cells and there is little information available about the presence of CCL28 in cancer. However, one report has shown that CCL28 mRNA expression was highly reduced or eliminated in human breast tumours compared to normal adjacent tissue (14) but the relevance of this still remains to be defined.

Further investigations are essential to clarify whether the suppression and secretion of CCL28 protein are related to colorectal carcinogenesis and carry significant clinical relevance. The results presented here comprise the initial stage of a forthcoming study on immunological features in CRC in our laboratory.

\section{Acknowledgements}

This work was supported by grants from the County Council of Jönköping, Sweden and the University College of Health Sciences, Jönköping, Sweden.

\section{References}

1. Fearon ER and Vogelstein B: A genetic model for colorectal tumorigenesis. Cell 61: 759-767, 1990.

2. Smith G, Carey FA, Beattie J, Wilkie MJ, Lightfoot TJ, Coxhead J, Garner RC, Steele RJ and Wolf CR: Mutations in APC, Kirsten-ras, and p53 - alternative genetic pathways to colorectal cancer. Proc Natl Acad Sci USA 99: 9433-9438, 2002.

3. Hakansson L, Adell G, Boeryd B, Sjogren F and Sjodahl R: Infiltration of mononuclear inflammatory cells into primary colorectal carcinomas: an immunohistological analysis. Br J Cancer 75: 374-380, 1997.

4. Balkwill $\mathrm{F}$ and Mantovani A: Inflammation and cancer: back to Virchow? Lancet 357: 539-545, 2001.

5. Coussens LM and Werb Z: Inflammation and cancer. Nature 420: 860-867, 2002

6. Lin EY, Nguyen AV, Russell RG and Pollard JW: Colonystimulating factor 1 promotes progression of mammary tumors to malignancy. J Exp Med 193: 727-740, 2001.

7. Balkwill F: Chemokine biology in cancer. Semin Immunol 15: 49-55, 2003

8. Dwinell MB, Johanesen PA and Smith JM: Immunobiology of epithelial chemokines in the intestinal mucosa. Surgery 133: 601-607, 2003.

9. Luster AD: Chemokines regulate lymphocyte homing to the intestinal mucosa. Gastroenterology 120: 291-294, 2001.

10. Pan J, Kunkel EJ, Gosslar U, Lazarus N, Langdon P, Broadwell K, Vierra MA, Genovese MC, Butcher EC and Soler D: A novel chemokine ligand for CCR10 and CCR3 expressed by epithelial cells in mucosal tissues. J Immunol 165: 2943-2949, 2000.

11. Wang W, Soto H, Oldham ER, Buchanan ME, Homey B, Catron D, Jenkins N, Copeland NG, Gilbert DJ, Nguyen N, Abrams J, Kershenovich D, Smith K, McClanahan T, Vicari AP and Zlotnik A: Identification of novel chemokine (CCL28), which binds CCR10(GPR2). J Biol Chem 275: 22313-22323, 2000.

12. Ogawa H, Iimura M, Eckmann L and Kagnoff MF: Regulated production of the chemokine CCL28 in human colon epithelium. Am J Physiol Gastrointest Liver Physiol 287: G1062-G1069, 2004.

13. Hieshima K, Ohtani H, Shibano M, Izawa D, Nakayama T, Kawasaki Y, Shiba F, Shiota M, Katou F, Saito T and Yoshie O: CCL28 has dual roles in mucosal immunity as a chemokine with broad-spectrum antimicrobial activity. J Immunol 170: 1452-1461, 2003.

14. Mickanin CS, Bhatia U and Labow M: Identification of a novel beta-chemokine, MEC, down-regulated in primary breast tumors. Int J Oncol 18: 939-944, 2001.

15. Bollag DM, Rozycki MD and Edelstein SJ: Protein Methods. Wiley-Liss, New York, 1996.

16. Kunkel EJ, Cambell JJ, Haraldsen G, Pan J, Boisvert J, Roberts AI, Ebert EC, Vierra MA, Goodman SC, Genovese MC, Wardlaw AJ, Greenberg HB, Parker CM, Butcher EC, Andrew DP and Agace WW: Lymphocyte CCR9 and epithelial TECK expression distinguish the small intestinal immune compartment: epithelial expression of tissue-specific chemokines as an organizing principle in regional immunity. J Exp Med 192: 761-768, 2000. 
17. Papadakis KA, Prehn J, Nelson V, Cheng L, Binder SW, Ponath PD, Andrew DP and Targan SR: The role of thymusexpressed chemokine and its receptor CCR9 on lymphocytes in the regional specialization of the mucosal immune system. J Immunol 165: 5069-5076, 2000.

18. Wurbel M-A, Philippe J-M, Nguyen C, Victorero G, Freeman T, Wooding P, Miazek A, Mattel M-G, Malissen M, Jordan BR, Malissen B, Carrie A and Naquet P: The chemokine TECK is expressed by thymic and intestinal epithelial cells and attracts double-and single-positive thymocytes expressing the TECK receptor CCR9. Eur J Immunol 30: 262-271, 2000.

19. Hieshima K, Kawasaki Y, Hanamoto H, Nakayama T, Nagakubo D, Kanamaru A and Yoshie O: CC chemokine ligands 25 and 28 play essential roles in intestinal extravasation of $\operatorname{IgA}$ antibody-secreting cells. J Immunol 173: 3668-3675, 2004.
20. Landi S, Moreno V, Gioia-Patricola L, Guino E, Navarro M, De Oca J, Capella G and Canzian F: Association of common polymorphisms in inflammatory genes interleukin (IL)6, IL8, tumor necrosis factor alpha, $\mathrm{NF}_{\kappa} \mathrm{B} 1$, and peroxisome proliferatoractivated receptor gamma with colorectal cancer. Cancer Res 63: 3560-3566, 2003.

21. Ohta M, Tanaka F, Yamaguchi H, Sadanaga N, Inoue H and Mori M: The high expression of Fractalkine results in a better prognosis for colorectal cancer patients. Int J Oncol 26: 41-47, 2005.

22. Wågsäter D, Hugander A and Dimberg J: Expression of CXCL16 in human rectal cancer. Int J Mol Med 14: 65-69, 2004.

23. Kunkel EJ and Butcher EC: Chemokines and tissue-specific migration of lymphocytes. Immunity 16: 1-2, 2002. 